\title{
ABCD Type 1 Diabetes Clinical Collaborative-UK
}

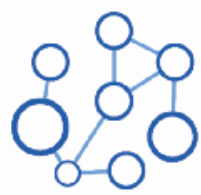

\author{
ROBERT GREGORY
}

The Association of British Clinical Diabetologists ( $A B C D$ ) has consistently promoted the need to ensure the highest quality care for people with type 1 diabetes. In 2012 it ran a campaign to raise awareness of their plight under the banner 'The Lost Tribe'. This arose from concerns that people with type 1 diabetes had inadvertently been let down by wholesale system change, repatriating people from secondary care diabetes clinics to primary care. While the preparation for this included up-skilling primary care teams to manage people with type 2 diabetes and to recognise those requiring specialist input, many people with type 1 diabetes were repatriated to teams that lacked a specialist understanding of their needs, and have subsequently been denied access to specialist care because they are meeting their glycaemic targets. People with type 1 diabetes are particularly sensitive to imprecise language used by some healthcare professionals, politicians and the press, which implies that their diabetes could have been prevented by eating less and being more physically active.

The outcome data for type 1 diabetes across the UK were disappointing. The National Diabetes Audit has repeatedly demonstrated that, for England and Wales, people with type 1 diabetes are less likely to receive the nine care processes and less likely to achieve treatment targets than people with type 2 diabetes. ${ }^{1}$ It has also found a worrying sevenfold increase in mortality in young women with type 1 diabetes. ${ }^{2}$ The reasons behind these observations are multiple and complex, but specialist diabetes teams and primary care teams should work together to increase accessibility and encourage patient engagement, as all too often patients seem unwilling to attend the care that is on offer in any setting.

All is not gloom: improvements in achievement of care processes and treatment targets in children in England have followed the introduction of a national paediatric diabetes network and a best practice tariff for children and adolescents with type 1 diabetes. ${ }^{3}$ The Scottish Diabetes Surveys have shown improvements in the diabetes control for people with type 1 diabetes, and the national investment in insulin pump therapy is likely to accelerate this. ${ }^{4}$

ABCD produced a position statement, updated in 2017, on the standards of care for the management of adults with type 1

Chair of ABCD Type 1 Diabetes Clinical Collaborative-UK

Address for correspondence: Dr Robert Gregory

Diabetes Outpatient Department, University Hospitals of Leicester NHS

Trust, Leicester General Hospital, Gwendolen Road, Leicester, LE5 4PW, UK.

E-mail: rob.gregory@uhl-tr.nhs.uk

Br J Diabetes 2018;18:1-2

https://doi.org/10.15277/bjd.2018.162 diabetes. ${ }^{5}$ This outlines the basics of care that should be delivered to people with type 1 diabetes, irrespective of where that care is delivered. The document is designed to complement national guidance, in particular the NICE 2015 guideline 'Type 1 diabetes in adults: diagnosis and management'. In England the NHS RightCare Pathway for Diabetes has drawn on these documents for its section on type 1 diabetes, ${ }^{6}$ which is important because it is intended to help commissioners (purchasers of healthcare in England) to understand the problem - or 'national opportunity' as it prefers to describe it - what a good service looks like and what to expect year on year from a good service. Diabetes Specialist Teams will increasingly be held accountable for the process and outcome data for the type 1 diabetes population in their catchment area, so there is an urgent need to gather data about our services, reflect on it and use it as an incentive to improve.

The ABCD T1 Diabetes Clinical Collaborative-UK (T1DCC-UK) materialised from discussions between $A B C D$ and Diabetes UK at which Rowan Hillson, former National Clinical Director for Diabetes, proposed a UK-wide network for specialist type 1 multiprofessional teams. The title came from the steering group, as did the mission statement: 'To ensure that everyone with type 1 diabetes has access to a suitably-trained multidisciplinary specialist team for expert assessment, care and support for self-management'. ABCD agreed to host the Collaborative and offered pages on its website. We want to identify the number of organisations providing specialist type 1 diabetes care, irrespective of where that care is delivered; to ensure that specialist multidisciplinary diabetes teams across the UK deliver care according to the current standards; to share and promote good and innovative practice in the field of type 1 diabetes. Our aim is to have a Clinical Lead for type 1 diabetes in each unit who will be responsible for providing data annually about the service for benchmarking purposes, completing a self-assessment survey of the type 1 service, including staffing numbers and training undertaken by staff specifically in type 1 diabetes competencies.

The Collaborative has six themed work streams:

- Pumps and technologies: The established and successful ABCD Insulin Pump Network-UK will be part of the Collaborative and will fulfil this function. This work stream has contributed to the introduction of Flash Glucose Monitoring across the NHS.

- Healthcare professional education, training and workforce issues: This will look at the composition and training of members of the multidisciplinary team. Diabetes UK has offered the Collaborative a parallel session at its 2018 Professional Conference, and the first webinar on the subject of Flash and Continuous Glucose Monitoring was well received. ${ }^{7}$ 
- Patient education: This will be concerned with ensuring that approved education is available at diagnosis and at other relevant times for every adult with type 1 diabetes. This will cover formal structured education programmes supplemented by easily accessible online courses and material.

- Whole of life: The Collaborative will address care delivered from transitioning of young people from paediatric diabetes care through to the end-of-life.

- Enabling success: The Collaborative will support and empower people with type 1 diabetes to achieve their potential.

- Quality improvement: The Collaborative will facilitate a UKwide approach to data collection, analysis and presentation in ways that will encourage continuous improvement in processes and outcomes.

Key stakeholders are represented in the Collaborative, including Diabetes UK, JDRF, TREND, PCDS, the DAFNE Collaborative, as well as the NHS in the four nations. Three patient representatives have been recruited.

Any healthcare professional working in a UK-based team currently providing care to people with type 1 diabetes is eligible to register free-of-charge to join the Collaborative and receive regular electronic mailings about its activities. It is very important that the Clinical Lead for type 1 diabetes in every organisation registers and identifies themselves as the Lead Clinician. This can be any healthcare professional, not necessarily a doctor. If your organisation does not have a Clinical Lead for type 1 diabetes, then please consider creating such a role.

\section{Conflict of interest None.}

\section{References}

1. NHS Digital. National Diabetes Audit, 2015-2016. Report 1: Care processes and treatment targets. https://digital.nhs.uk/media/30447/National-Diabetes-Audit-2015-2016-Report-1-Care-Processes-and-Treatment-Targets-/Any/nati-diab-rep1-audi-2015-16 (accessed 5 March 2018).

2. NHS Digital. https://digital.nhs.uk/media/31683/National-Diabetes-Audit2015-16-Report-2a-pdf (accessed 5 March 2018).

3. HQIP/RCPCH. National Paediatric Diabetes Audit, 2015-16. Report 1 Care processes and outcomes. https://www.rcpch.ac.uk/system/files/protected/page/Complete\%20NPDA\%202015-16\%20report\%20FINAL_0. pdf (accessed 5 March 2018).

4. http://www. diabetesinscotland.org.uk/Publications/Scottish\%20Diabetes\%20Survey\%202016.pdf (accessed 5 March 2018).

5. Association of British Clinical Diabetologists (ABCD). Standards of care for management of adults with type 1 diabetes. http://www. diabetologists-abcd.org.uk/Position_Papers/Type_1_standards_of_care_2017.pdf (accessed 5 March 2018).

6. NHS RightCare. NHS RightCare Pathway: Diabetes. https://www.england.nhs.uk/rightcare/wp-content/uploads/sites/40/2017/06/nhs-rightcare-pathway-diabetes-v2.pdf (accessed 5 March 2018).

7. Association of British Clinical Diabetologists (ABCD). Webinars. https:// abcd.care/webinars (accessed 5 March 2018). 